\title{
Review
}

\section{The Future of Factories: Different Trends}

\author{
Giulio Salierno ${ }^{1, *(\mathbb{D})}$, Letizia Leonardi ${ }^{1,2}$ (D) and Giacomo Cabri ${ }^{2,3}$ (D) \\ 1 Department of Engineering "Enzo Ferrari", University of Modena and Reggio Emilia, 10, Via P. Vivarelli, \\ 41125 Modena, Italy; letizia.leonardi@unimore.it \\ 2 CINI Embedded Systems \& Smart Manufacturing National Lab, Via Ariosto, 25, 00185 Roma, Italy; \\ giacomo.cabri@unimore.it \\ 3 Department of Physics, Informatics and Mathematics, University of Modena and Reggio Emilia, 213/B, \\ Via Campi, 41125 Modena, Italy \\ * Correspondence: giulio.salierno@unimore.it
}

\section{check for}

updates

Citation: Salierno, G.; Leonardi, L.; Cabri, G. The Future of Factories: Different Trends. Appl. Sci. 2021, 11, 9980. https://doi.org/10.3390/ app11219980

Academic Editor: Paolo Renna

Received: 20 September 2021

Accepted: 21 October 2021

Published: 25 October 2021

Publisher's Note: MDPI stays neutral with regard to jurisdictional claims in published maps and institutional affiliations.

Copyright: (c) 2021 by the authors. Licensee MDPI, Basel, Switzerland. This article is an open access article distributed under the terms and conditions of the Creative Commons Attribution (CC BY) license (https:// creativecommons.org/licenses/by/ $4.0 /)$.
Abstract: The technological advancements promote the rise of the fourth industrial revolution, where key terms are efficiency, innovation, and enterprises' digitalization. Market globalization, product mass customization, and more complex products need to reflect on changing the actual design methods and developing business processes and methodologies that have to be data-driven, AI-assisted, smart, and service-oriented. Therefore, there is a great interest in experimenting with emerging technologies and evaluating how they impact the actual business processes. This paper reports a comparison among the major trends in the digitalization of a Factory of the Future, in conjunction with the two major strategic programs of Industry 4.0 and China 2025. We have focused on these two programs because we have had experience with them in the context of the FIRST H2020 project. European industrialists identify the radical change in the traditional manufacturing production process as the rise of Industry 4.0. Conversely, China mainland launched its strategic plan in China 2025 to promote smart manufacturing to digitalize traditional manufacturing processes. The main contribution of this review paper is to report about a study, conducted and part of the aforementioned FIRST project, which aimed to investigate major trends in applying for both programs in terms of technologies and their applications for the factory's digitalization. In particular, our analysis consists of the comparison between Digital Factory, Virtual Factory, Smart Manufacturing, and Cloud Manufacturing. We analyzed their essential characteristics, the operational boundaries, the employed technologies, and the interoperability offered at each factory level for each paradigm. Based on this analysis, we report the building blocks in terms of essential technologies required to develop the next generation of a factory of the future, as well as some of the interoperability challenges at a different scale, for enabling inter-factories communications between heterogeneous entities.

Keywords: digital factory; virtual factory; cloud manufacturing; Industry 4.0; China 2025

\section{Introduction}

The digitalization of a factory is deeply impacted by the new trends emerging under the umbrella of programs developed in the on-going fourth industrial revolution, which aims to automatize traditional manufacturing process and systems, taking benefits from the modern technologies developed by the ICT. Digitalization includes the application of technologies at a different scale, shifting from software downing to infrastructure, and systems to revolutionize traditional production processes and business. In this scenario, different programs have emerged to identify major trends in the digitalization of a factory. Thanks to our involvement in the FIRST H2020 project (vF Interoperation suppoRting buSiness innovaTion) (https: / / www.h2020first.eu, accessed on 24 October 2021), we had experience concerning the European program Industry 4.0 and the Chinese program China 2025; the FIRST project is a mobility project that involves European and Chinese universities and companies, focusing on virtual factories. We did not find a comparison in the literature between the two programs, in our opinion because of the difficulties of consulting Chinese 
documents and repositories, so we decided to compare them. Therefore, in this review paper, we report about our work. European industrialists identify the radical change in the traditional manufacturing production process as the rise of Industry 4.0 [1]. Conversely, China mainland launched its strategic plan China 2025 to promote smart manufacturing as an objective for digitalizing traditional manufacturing processes.

On the one hand, the digitalization of factories is considered a revolution that will bring a lot of benefit to factories, so it has attracted a lot of attention, both from entrepreneurs and from researchers [2]; on the other hand, there are sparse and different approaches that have common as well as different aspects. The latter makes it difficult to choose the most appropriate approach, because of the lack of standards and of the difficulties in understanding the pros and cons for the specific factory. From the above considerations, this scenario calls for investigation.

Industry 4.0 and China 2025 programs share the goal of realizing the next Factory of the Future towards the development of an ICT-enabled intelligent manufacturing [3,4]. In these two programs, the link between industrial machines, humans, and manufacturing systems is achieved by forming virtual collaborative networks to quickly respond to the market changes supported by Cyber-Physical Systems (CPS) as the system's backbone. They enable the integration of all resources related to the manufacturing process. The traditional Product Lifecycle Management (PLM) is the process of managing the entire product lifecycle of the supply chain. This process ranges from the preliminary activity, such as product prototyping, down to product design and its realization. Data originated from the activities of PLM mainly focuses on physical products rather than virtual models. The lack of convergence between physical products and virtual models gets data in the product lifecycle isolated, fragmented, and stagnant, which is useless for manufacturing enterprises [2]. In this scenario, Cyber-Physical Systems (CPS) have the central role of enabling a digital twin model. One of the key aspects of the digital twin model is establishing a link between physical products and virtual models. The digital twin model enables the designer to test, predict, and verify product performance by simulating a design scheme and manufacturing process before diving into the production process. A general definition of the Digital Twin model is given by [5] as: "Digital twin model is an integrated multi-physics, multi-scale, probabilistic simulation of a complex product and uses the best available physical models, sensor updates, to mirror the life of its corresponding twin".

To this end, the digital twin model consists of three parts. A physical part where products and manufacturing assets compose the existing shop floor layer. A virtual part where virtual models of products and manufacturing assets enable constructing a virtual model to test, simulate, and verify product performances. The last part is a link between the physical layer and the virtual layer to synchronize and integrate the physical and the virtual world. To address this new shortcoming, a paradigm shift is needed to build the next generation of Factory of the Future.

The digital-twin-driven manufacturing process enables industries to face new challenges arisen from the change of market requirements. For example, the new emerging trend known as product mass customization puts final customers at the center of the manufacturing process by allowing mass customization of products. The driven digital-twin manufacturing process fits these requirements by allowing industries to rapidly change manufacturing processes or customize them according to customer requirements. The implementation of the digital twin model is addressed at different layers of the supply chain.

The main contribution of this review paper is to report about the investigation of the state-of-the-art w.r.t. paradigms, frameworks, and tools to realize the digital twin model in the two considered programs, i.e., Industry 4.0 and China 2025. In this sense, different literature trends identify new paradigms for the realization of the factory of the future. The paradigm Virtual Factory (VF) has been used primarily referring to European factories, Digital Factories (DF) and Smart Factories (SF) paradigms having a widespread in European and China, and Cloud Manufacturing ( $\mathrm{Cmfg}$ ) known as a new paradigm for the digitalization of Chinese industries taking its advantage from the cloud computing 
paradigm. In our study, we point out the common aspects of the approaches as well as the differences among them, comparing in particular Cloud Manufacturing and Virtual Factories. As a final contribution of our study, we envision the building blocks of the factories of the future comprising multiple technologies at a different scale. In particular, we analyzed core technologies which promote the digitalization of the supply chain, as well as some interoperability issues to address while enabling inter-factories cooperation.

The paper is organized as follows. We introduce in Section 2 the methodology adopted in this research to extract relevant papers in the field. Then, we introduce the characteristics of Digital Factories, discussing their extensibility as Smart and Virtual Factories (Section 3), then we describe the Cloud Manufacturing, providing an example of its application (Section 4). Starting from the above descriptions, we propose in Section 5 a comparison between Virtual Factory and Cloud Manufacturing, while Section 6 highlights the main architectural components for the enablement of a factory of the future, starting from the paradigms examined in the previous sections. Some of the interoperability challenges to enable seamless inter- and intra-factory communications are presented. Finally, Section 7 collects some discussions and the conclusions about our study, and sketches some future works.

\section{Research Method}

To measure how widespread these paradigms are, we performed a literature count within two different databases to collect and identify relevant works on the topic. Google Scholar (https: / / scholar.google.com/, accessed on 24 October 2021), which indexes scientific literature, has been employed to identify articles from a European Perspective. Conversely, the popular Chinese search engine Baidu Scolarly (https:/ / xueshu.baidu.com/, accessed on 24 October 2021), which indexes scientific literature written in the Chinese language, has been employed to identify relevant literature on the topic from Chinese scientific journals.

As most of the scientific journals in China are not published in English, much of the current scientific development is not readily available to non-Chinese-speaking scientists [6].

To overcome the language barrier, we employed some of the automatic translation tools, such as Google Translate (https: / / translate.google.com/, accessed on 24 October 2021), to be able to identify the keywords reported in Table 1 for non-English literature.

Table 1. Keywords in English and Chinese languages for identification of trends in FoF.

\begin{tabular}{ll}
\hline Keyword-EN & Keyword-CH \\
\hline Digital Factory & 数字化工厂 \\
\hline Smart Factory & 智能工厂 \\
\hline Cloud Manufacturing & 制造 \\
\hline Virtual Factory & 虚拟工厂 \\
\hline
\end{tabular}

We applied the following searching criteria for restricting research results on search engines: (i) period-filter works on the time frame that ranges from 2017 to 2019. (ii) work titles. It requires that the keyword appears in the work title, thus avoiding retrieving articles out of the scope (i.e., articles that occasionally mention the keyword). The same research parameters have been applied to both search engines by specifying the same filters. Finally, to avoid results overlapping, we restricted results on Google Scholar and Baidu Scholar by filtering only articles written in English and Chinese.

The keywords reported in Table 1 produce the results represented in Figure 1. The search of keywords "Cloud Manufacturing" and "Smart Factory", respectively, produce $(607,413)$ and $(686,890)$ match on both search engines, which indicates an emerging trend of these paradigms over the three years. Keywords "Digital Factory" and "Virtual 
Factory" produce the following matches: $(151,171)$ and $(79,111)$. We followed the twostate approach described by [7] to select quality and relevant articles by determining the following characteristics: (i) keywords, (ii) scope of the work, (iii) goal, (iv) content, and (v) relevance to the field. During the first round, we obtained many results for "Cloud Manufacturing" and "Smart Factory" while we obtained few for the other two paradigms. Therefore, during the second round of search, we applied more search filters. For Smart Manufacturing and Cloud Manufacturing, we reduced the matching results by specifying more matching criteria. We removed works that occasionally cite the keywords without discussing them. In addition, we expanded the publication time for "Digital and Virtual Factories", considering the time frame 2012-2018 as obtaining more relevant results. The second round produces 58 research works that were grouped into four categories [8] based on the topic.

1. "Concept and perspectives" includes 22 selected research works to define scope, goal, and perspectives in the application of "Digital Factory", "Virtual Factory", and "Cloud Manufacturing".

2. "Interoperability" contains 9 selected works that outline major challenges in the integration between virtual and real factory, as well as challenges arisen during the integration of different paradigms (i.e., transition from digital to smart factory).

3. "Key technologies" includes 14 research works to describe the most attractive technologies for implementing a Cyber-Physical System of a Factory of the Future.

4. "Applications in Industry" contains 11 relevant works in which authors report their experience in realizing systems for Industry 4.0. In the next sections, we describe Digital Factories, Virtual Factories, and Cloud Manufacturing characteristics.

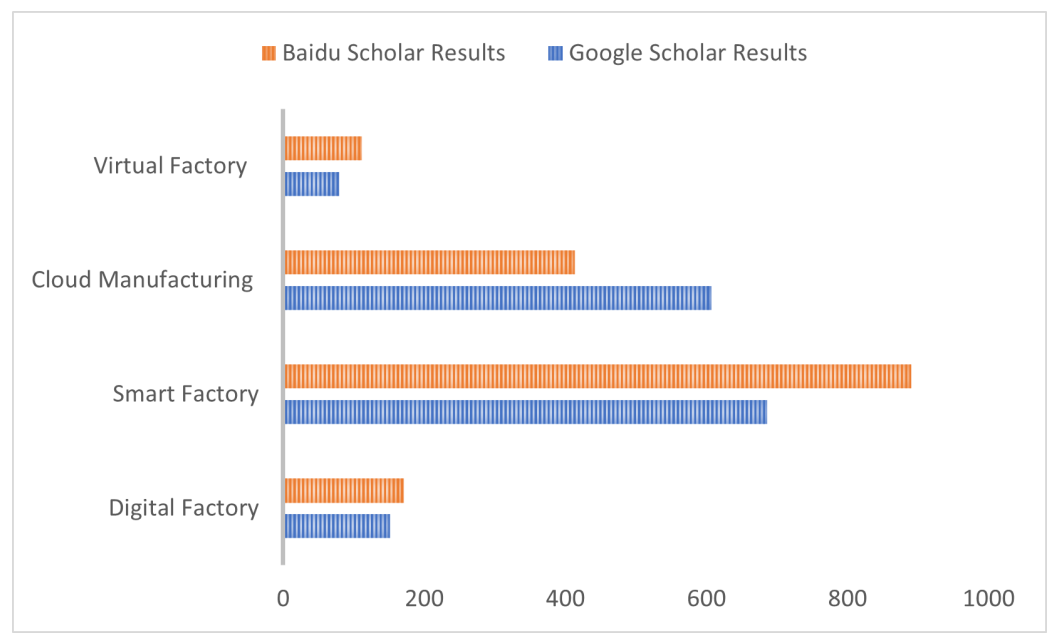

Figure 1. Matching results on search engines of keywords reported in Table 1.

In the following, we analyze the main characteristics of the four approaches reported in Table 1.

\section{Characteristics of Digital Factory}

A digital factory refers to a new type of manufacturing production organization that simulates, evaluates, and optimizes the production processes and systems. Digital factories are not confined only to the production stage; instead, they extend to address the entire product lifecycle.

The production process in a digital factory occurs from the early stage of product design down to the lowest stage of product planning and realization. As key features of the design stage, digital design, modeling, and simulations contribute to shortening the time for designing and manufacturing products [9].

Models and simulations are extended to all tangible and intangible assets of the factory. 3D-motion simulation is applied to virtual models on various stages to improve the product 
and process planning on each level [10]. The digital factory represents a bridge for the existing gap between product design and manufacturing [11]. Thus, the digital factory covers the entire product lifecycle at different manufacturing levels, focusing on the virtual representation of the factory's manufacturing assets, virtual plant visualization, intelligent control, and optimization of the product lifecycle through model simulation.

To this end, the digital twin model is based on different models representing physical manufacturing assets (i.e., 3D-model, discrete event model) and virtual simulation technology to simulate and predicts the performance of virtual models, as well as an integration platform to realize two-way connectivity between digital and real factory [12].

In the digital factory, the product design shifts from traditional 2D drawings to a collaborative 3D model design based on CAD [13]. In this context, it enhances the following aspects: (i) product performances (i.e., manufacturability, cost) are predicted by model simulations, thus the entire manufacturing process is optimized; (ii) product design is collaborative, meaning that multiple design departments (within the company boundaries) take part in the product design.

One of the significant concepts of a digital factory is representing the physical objects composing the shop floor in a virtual space. The connection between the physical and the virtual world of a factory is realized through virtual models [14].

3D-Virtual Reality (VR) technologies replicate the shop floor in a virtual space, and simulation results optimize the design process without the need for sample manufacturing. Through three-dimensional modeling and virtual simulation technology, the design layer predicts the production performance and improves and optimizes the product life-cycle based on simulation results.

The digital factory's core is represented by the integration of existing manufacturing systems at different operational layers and the adoption of 3D modeling technologies, virtual simulation, and Virtual Reality/Augmented Reality technologies. The digital factory promotes technological support for the entire product life cycle by creating a digital twin model.

To this end, the authors of [15] propose a framework that enables the development of a feasible semantic model that supports the easy creation of digital twins for physical assets of a factory. The shop floor hardware virtualization encompasses a data model that encapsulates the machines technical specifications composing the factory floor.

Conversely, at the control layer, virtual simulation plays a central role in modern manufacturing companies that adopt virtual reality to design and verify production systems such as machine simulation, process verification, and factory layout planning and simulation. Simulation of virtual resources is made available through a variety of commercial tools such as Arena [16], DELMIA [17], and Flexsim [18]. For example, South Korea's Samsung Heavy Industries use DELMIA software to build a 3D layout of the factory floor and simulate the shipbuilding process in a virtual environment, from the concept down to the deployment [19].

The model-based simulation also helps to identify bottlenecks in the production line whose identification in the real world would have required a long-term verification with high costs (i.e., to maximize the production by reducing the number of failures caused by poor processes and failures of mechanical parts). As an example, authors in [20] built a Flexsim model starting from real data of a packaging production line. The model helped in identifying machine failures of the hardware composing the shop floor. Therefore, continuously updating simulation models with monitoring data improves the accuracy and precision of the predictions [21].

In addition, the recent advancements in the field of Augmented reality helps to solve common problems in the manufacturing plant. The increasing cost of labor and the loss of knowledge due to the retirement of highly skilled employees are minimized by adopting Augmented Reality technologies. As an example, AR is used to train newcomers by providing visual training on mastering manufacturing equipment. Information is displayed directly on the eye screen through the use of standard AR glasses. This approach 
reduces the cost of training newcomers and enables the instruction of employees to handle hardware failures by displaying procedures to recover from failures, thus improving the maintenance. As a result, Augmented Reality has been successfully employed towards assembly tasks in the manufacturing plants [22].

\subsection{From Digital to Smart Factory}

The design of an intelligent shop floor layer of a digital factory is related to the new concept of a smart factory. A digital factory is the key enabler of a smart factory for the next generation of a Factory of the Future. A smart factory connects the main actors of the supply chain (people, products, and materials) to realize seamless communication and integration (man-and-machine) for the smart manufacturing realization. The adoption of high-end manufacturing equipment (i.e., smart devices, industrial robots, and robotic arms) and the integration of well-established equipment with IoT devices and sensors allows collecting real-time data and information from the factory floor. Smart factory adds decision-making capabilities to the shop floor, and data collected from equipment is analyzed to improve the lowest manufacturing layer's production process.

In the literature, many definitions of smart factories are given. A most inclusive one defines a smart factory as [23]: "a manufacturing solution that provides such flexible and adaptive production processes that will solve problems arising on a production facility with dynamic and rapidly changing boundary conditions in a world of increasing complexity. This special solution could, on one hand, be related to automation, understood as a combination of software, hardware and/or mechanics, which should lead to optimization of manufacturing resulting in reduction of unnecessary labor and waste of resource. On the other hand, it could be seen in a perspective of collaboration between different industrial and nonindustrial partners, where the smartness comes from forming a dynamic organization". Authors highlight this system's potential to enable cooperation between industry stakeholders and the optimization of manufacturing processes.

For a smart factory, the digital factory represents a necessary prerequisite for its enablement. A smart factory is, in turn, necessary for the development of the next generation of smart manufacturing. Within a smart factory, the digital factory's capabilities are improved by adding an extra layer that provides real-time data from the shop floor, thus simplifying the construction of faithful 3D models of the digital factory. The shop floor data collection enables the digital factory to better design models, improving accuracy as well as simulation results (see Figure 2).

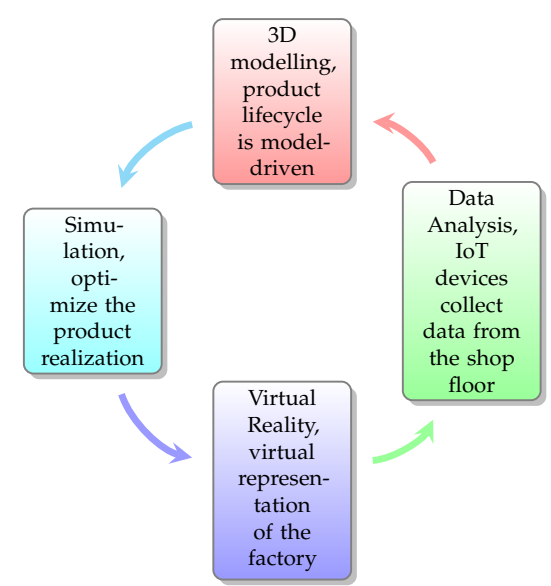

Figure 2. Digital Factory lifecycle. The Smart factory enables data sensing from the shop floor.

In implementing a Smart Factory system, the Internet of Things (IoT) plays a key role. IoT sensors' data sensing enables the digital factory to enrich virtual models with real-time data inferred from the shop floor. Sensing capabilities improve model accuracy as well as provide real-time statistics about the manufacturing process of the supply chain. A sensing layer links the smart factory with existing applications of digital factories. 
Therefore, a smart factory requires both vertical interoperability between shop-floor automation devices and services, as well as horizontal interoperability between enterprises and cloud service platforms [24].

As an open challenge, the integration between smart and digital factory [25] requires to provide an interface between entities of the digital factories and IoT devices of the smart factory. The integration requires to guarantee semantic and functional interoperability between heterogeneous technologies. IT applications should be enabled to receive data from smart devices from the digital factory layer, process these data, and update the virtual models. From the smart factory layer, the devices should receive feedback produced by the digital factory to optimize the manufacturing processes and help to make better decisions. This requirement poses the challenges of enabling interoperability on three levels [26]: (i) data transfer protocols, (ii) semantic of data, and (iii) data presentation.

A proposed reference model for enabling interoperability among different assets of Industry 4.0. is the Reference Architectural Model Industry 4.0 (RAMI 4.0) [27]. RAMI 4.0. has been employed as service-oriented reference architecture (see Figure 3) for implementing projects of Industry 4.0.

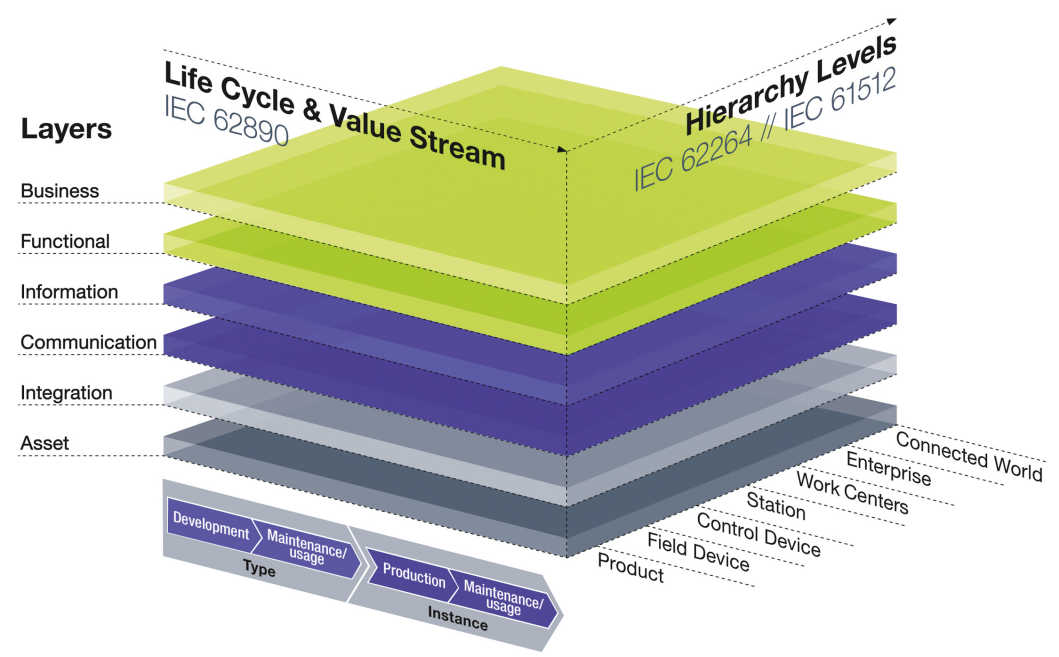

Figure 3. RAMI 4.0. Reference service-oriented architecture for Industry 4.0 [28].

RAMI 4.0. defines a service-oriented architecture (SOA) where applications are offered as a service and communicate over a network. The architecture aims to decouple complex application logic in order to communicate with each other through exposed services. Its architecture consists of three different axes views, each one describing a crucial aspect for industry 4.0 (see Figure 3).

The Hierarchy Levels axis positioned to the horizontal right axis refers to the standard IEC62264 / IEC61512, which defines standard functionalities for factories. This axis includes the label "Connected World", "Field Devices", and "Product". They refer to the connection between products and IoT within the factory, enabled by IoT sensing capabilities. Different IoT technologies are used to this purpose as field actuators (based on Remote Frequency Identifier RFID technology and IoT sensors forming Wireless Sensor Networks). These technologies act like an external service to its associated environment, referred to as horizontal integration (across the factories).

The Life Cycle \& Value Stream positioned to the left horizontal axis refers to the product life cycles based on IEC 62890. Each product in the factory has its life cycle, which requires physical and virtual assets. Physical assets include manufacturing machines, hardware, components, and tools. Virtual assets include software, operating systems, project files, and data. In RAMI 4.0. these criteria are maintained with differentiation between product "instances" and "types". When a product is being designed, it will be referred to as a type. When the product shifts from design to production, it will be referred to as an instance. 
Whenever a product needs to be redesigned or new features must be added, it will move again to the type state.

The layers on vertical axis represent the integration among six layers, ranging from business, functional, information, communication, integration, and asset.

Another reference architecture proposed for the deployment of IoT based industrial systems that are better built and integrated with a shorter time to market is the Industrial Internet Reference Architecture (IIRA) [29]. The architecture consists of 4 layers, each representing a specific viewpoint of the system (see Figure 4).

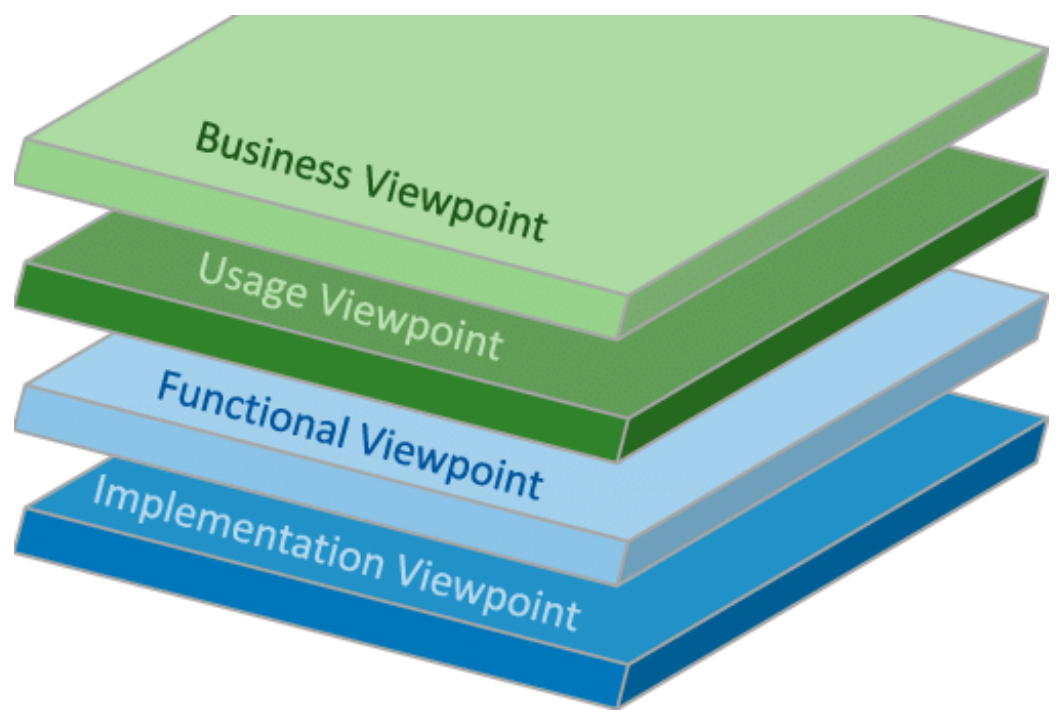

Figure 4. Industrial Internet Reference Architecture (IIRA) viewpoints for smart manufacturing [30].

The Business Viewpoint comprises the stakeholder requirements on the type of system they want to realize and its objectives. From a general perspective, it resembles all primary motivations on why to realize a specific type of system and how the end-users will use the system. The Usage Viewpoint comprises all the scenarios, as well as the behaviour of the system and its interactions. The next layer is the Functional Viewpoint, which includes all the system characteristics and the interrelation among system components as well as external actors. The last layer is the Implementation Viewpoint, which deals with the technologies needed to implement functional components.

Comparing the RAMI 4.0 and IIRA architecture described above, the Internet Reference Architecture proposed an alignment among the two architectures (https: / / www. iiconsortium.org/pdf/JTG2_Whitepaper_final_20171205.pdf, accessed on 24 October 2021) presented in Figure 5.

The IIRA Usage and Implementation Viewpoints are complementary to RAMI 4.0, as shown in Figure 5, since in the RAMI 4.0 reference model, there is no counterpart feature. The Business Viewpoint of IIRA is complementary to the RAMI 4.0 life cycle dimension as it includes additional concepts that are useful to better define the needs of the various actors and organizations involved in the product life cycle. The layer dimension of RAMI 4.0 is similar to the Functional Viewpoint, except that RAMI 4.0 is more specific to the manufacturing domain and, therefore, it fits better in manufacturing applications. The crosscutting functions and system characteristics of IIRA are, in that sense, complementary to the layer dimension. Connectivity is the only divergence found between the two reference models [30]. RAMI 4.0 focuses on a Service Oriented Architecture, while IIRA lacks a microservices-oriented communication schema. However, there are some similarities in the protocol stacks of the two reference models. 


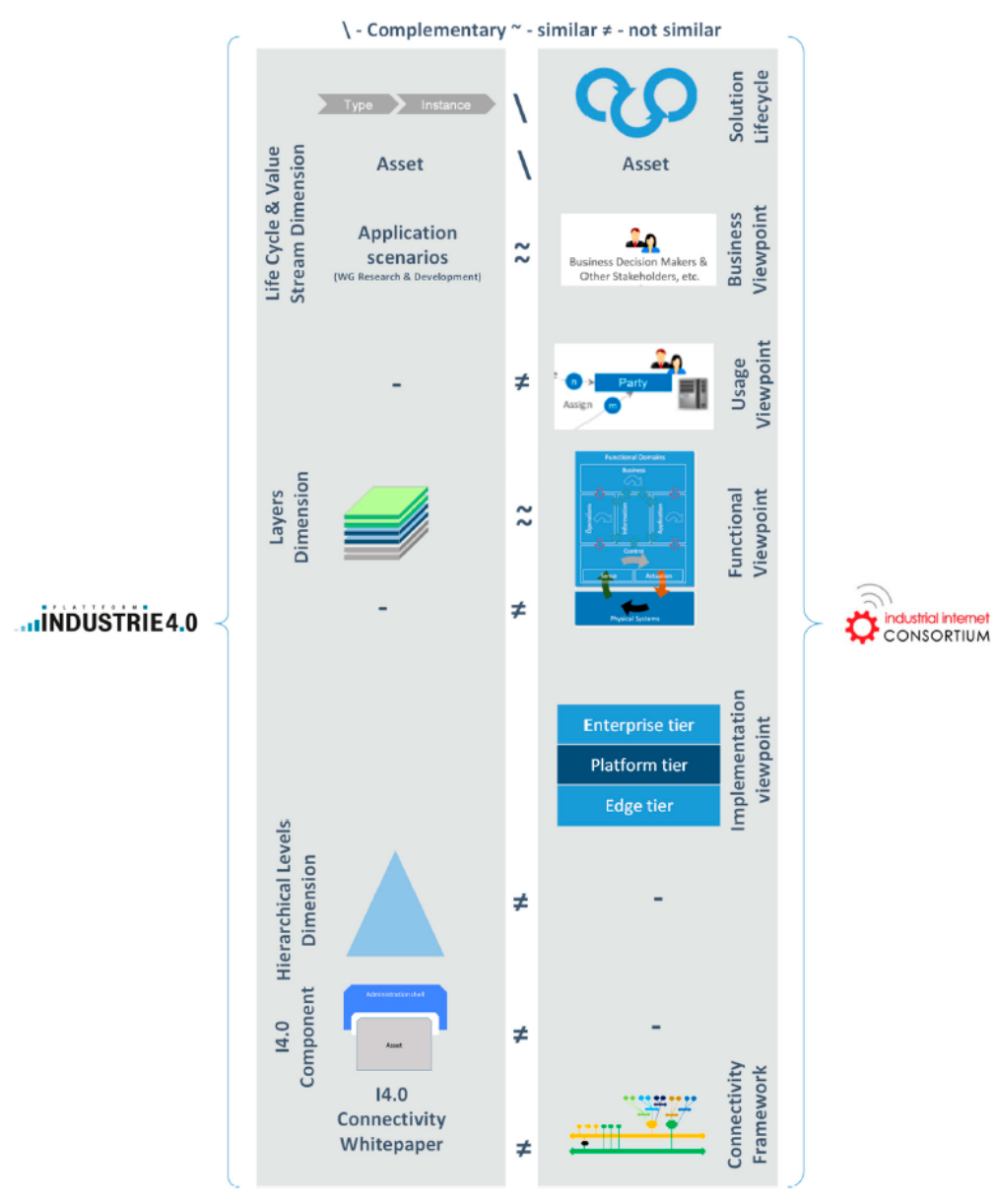

Figure 5. Industrial Internet Consortium alignment between RAMI 4.0 and IIRA [30].

\subsection{Relationship between Digital Factory and Virtual Factory}

The European concept of Virtual Factory is a major expansion upon virtual enterprises in manufacturing. The virtual organization approach integrates collaborative business processes from different enterprises to simulate, model, and test different design options to evaluate performance, thus to save time-to-production [31].

Both digital factory and virtual factories share common reference models for realizing a Factory of the Future. In a digital factory, decision-making technologies play a key role in real plant simulation and optimization.

Similar applications are found in a digital factory, where its implementation extends to design and production processes across multiple departments within the company boundaries. This trend emerges in companies that implement a digital factory to support a collaborative process among departments. For example, the China Aerospace Science and Technology 211 company adopts a full step-by-step design process, ranging from 3D-to-process to 3D-to-site and 3D-to-factory. It can be outlined that the adoption of 3D models drives process collaboration through the entire development process. Therefore, three-dimensional modeling is a key enabler of a collaborative process, promoting the sharing of product data flexibly within the digital factory boundaries.

Similarly, 3D virtual environments and discrete event simulation models are proposed for modeling, simulating, and evaluating manufacturing assets [31] in a virtual factory. In contrast, while a digital factory is likely to define its operational boundaries inside the company, a virtual factory extends the factory's capabilities across multiple organizations to provide a unified virtual environment to test, model, and simulate factory layouts and processes [32].

Ultimately, there is a strong overlap between the digital factory and the virtual factory. While the digital factory provides cooperation within departments, the virtual factory 
extends this cooperation among multiple enterprises. Therefore, for the rest of the chapter, we will refer to a virtual factory as an extension of the digital factory. The concept of collaborative manufacturing is also an important characteristic of cloud manufacturing described in the next section.

\section{Characteristic of Cloud Manufacturing}

Cloud manufacturing is an emerging trend popular in China, which benefits from cloud computing and information technology to achieve resource-sharing across small and medium-sized enterprises (SMEs). It has become a national trend due to rapid industrialization and the advancement of information technology. Cloud Manufacturing can be defined as a model for enabling ubiquitous, convenient, on-demand network access to a shared pool of configurable manufacturing resources (e.g., manufacturing software tools, manufacturing equipment, and manufacturing capabilities) that can be rapidly provisioned and released with minimal management effort or service provider interaction [33]. Therefore, on-demand services, resource virtualization, and decentralized services of centralized resources promote new networked manufacturing forms to respond quickly to unpredictable demands of the market. Cloud Manufacturing inherits the concept of "everything is a service" from cloud computing. It proposes a new paradigm of Manufacturing as a Service (MaaS), which encapsulates manufacturing assets (software tools, production systems, capabilities) into cloud services providing on-demand access to consumers. Further, cloud manufacturing promotes a new collaborative manufacturing business model, represented in Figure 6. Collaborative cloud manufacturing promotes the active role of the customers during the production process. Customers interact with manufacturers via a cloud platform by specifying their product requirements. Mass customization of products is enhanced by creating a network of enterprises Distributed Manufacturing Systems (DMS), having different roles in the production process.

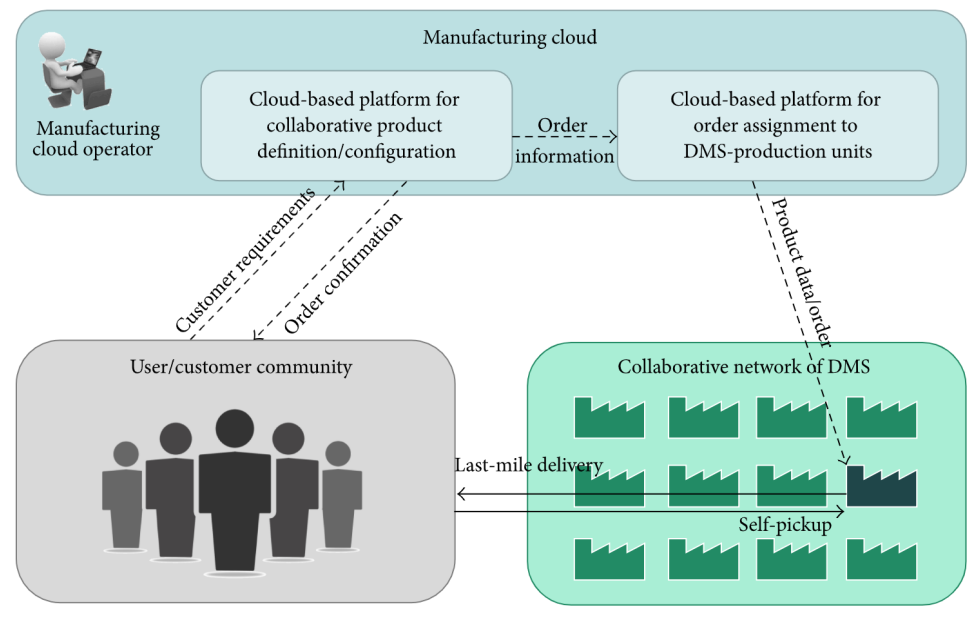

Figure 6. Collaborative cloud manufacturing model taken from [34].

The nature of services provided in the cloud is extremely variegated due to the necessity to cover the traditional manufacturing processes and the related products life cycle. According to [35], service delivery models (SDM) are typical of Cloud Computing, and they can be divided into: Infrastructure-as-a-Service (IaaS), Platform-as-a-Service (PaaS), and Software-as-a-Service (SaaS). In contrast to traditional cloud computing, services are provided both by cloud computing resources and manufacturing resources (smart robots, production systems, equipment). Services provided by the cloud can range from pure manufacturing services (i.e., equipment for product realization) to manufacturing software services (provided through a cloud computing resource). Cloud delivery models fit accordingly to the different manufacturing steps. As an example, considering the product life cycle, the following delivery models are suitable for the different production stages: 
- $\quad$ Product Design, Product Simulation, and Product Management delivered as SaaS

- $\quad$ Product Planning delivered as PaaS

- Product Realization (requiring the use of physical equipment composing the factory floor) delivered as IaaS

In addition to the standard cloud manufacturing services mode, cloud manufacturing promotes a new form of enterprises collaboration through the on-demand access of virtualized and decentralized resources via a cloud platform. For example, virtual enterprises set up a collaborative network that supports a different form of coupling, such as loose and tight coupling. According to the diverse enterprise needs, loose coupling is selected for occasional use of manufacturing assets, while a tight coupling is chosen whenever a global manufacturing process relies on services offered by multiple enterprises. Therefore, a cloud architecture promotes enterprise collaboration by enabling multiple forms of alliances according to diverse needs. Through the unified management of resources/capabilities, cloud manufacturing promotes the sharing of decentralized resources of manufacturing resources/capabilities highlighted by the manufacturing grid and includes integrating and sharing hard manufacturing resources.

Cloud manufacturing has four typical deployment modes inherited from cloud computing [33] (public cloud, private cloud, hybrid cloud, and community cloud).

- In the public cloud, service providers subscribe and publish their services in a multitenant environment. A cloud platform provides on-demand use of services to an open community of customers.

- $\quad$ Private cloud restricts the operational mode within enterprises boundaries. In a private cloud, all actors belong to the same organization.

- A community cloud is shared among companies which group together sharing the infrastructure.

- Hybrid cloud mixes the previous mode to integrate different types of cloud (e.g., public, private). Forming a bridge between different clouds requires cloud owners to select proper resources sharing models. Authors in [36] proposed a framework for the development of hybrid cloud, bridging multiple cloud platforms.

The success case of cloud manufacturing in China mainly includes small- and mediumsized enterprises that have established their information systems [37]. Despite the cloud manufacturing aims to cover the entire manufacturing product life-cycle, ranging from collaborative product design down to services integration and virtualization and sharing of manufacturing resources, at present, the development of a full-featured cloud manufacturing application case is still under development [35]. Nevertheless, many industries start to experiment with developing a cloud manufacturing platform at different levels of awareness. The collaborative cloud platform proposed in [38] aims to balance uneven resources distribution and fragmentation in the integration of different services in the mold industry. The cloud platform acts as a trading platform where enterprises publish and trade their manufacturing assets. The platform's main functionalities include enterprise registration as a service provider or customer, manufacturing assets registration, service discovery, service selection, service evaluation, and transaction management.

Similarly, the features of the platform are extended [39] to enable integration at the process level, as well as the tight coupling of different manufacturing management systems (i.e., MES, ERP). The collaboration model between enterprises is based on a social network model that guarantees interaction among partners in a relatively stable network environment. According to the diverse business requirements, enterprises seek new partners through the public market page, remove partners from an alliance, or join multiple networks simultaneously. The platform Tianzhi Net (www.cosimcloud.com, accessed on 20 September 2021) enables enterprises business collaboration of local industrial chains [39]. The example reported in Figure 7 shows a network alliance based on a social network model enabled by a cloud platform. 


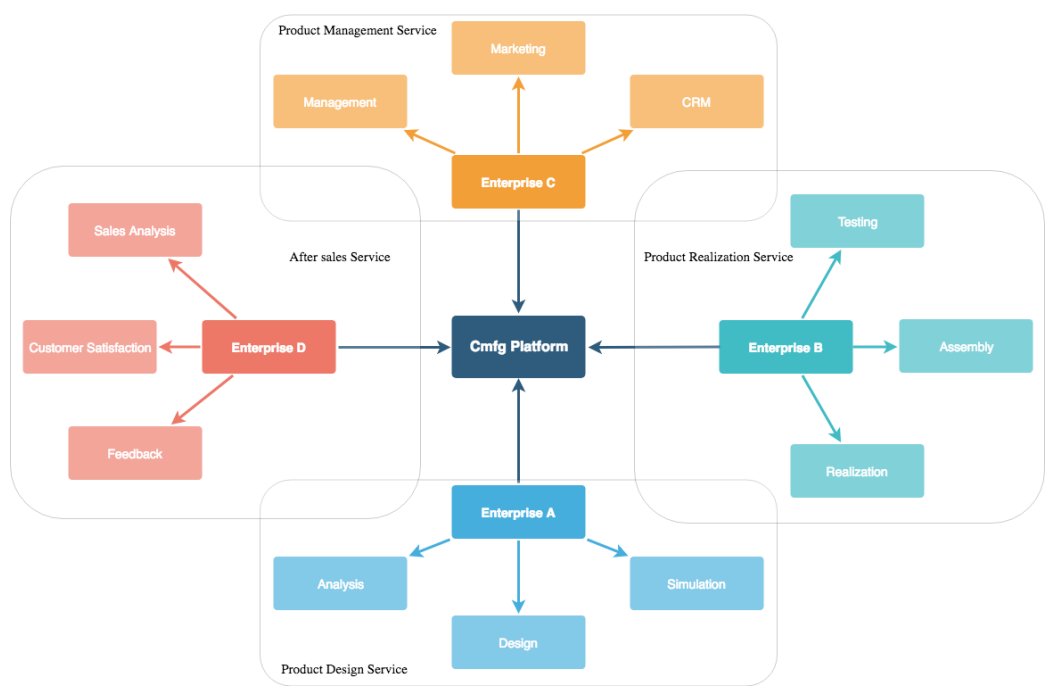

Figure 7. An example of a collaborative network established via a cloud platform.

\section{Comparison between $\mathrm{Cmfg}$ and $\mathrm{vF}$}

In this Section, we compare Cloud Manufacturing (Cmfg) and Virtual Factory (vF) based on some of their main features. Firstly we introduce the operational boundaries to examine the degree of interoperability across factories. We examine different approaches to provide interoperability at each architectural layer. Then, we describe the main actors of a vF and Cmfg. Finally, we briefly introduce potential applications for simulating and optimizing a factory. Table 2 summarizes this comparison. The comparison takes into consideration for each of the discussed paradigms the following characteristics: (i) Operational Boundaries (ii) Data Interoperability, (iii) Service interoperability, (iv) Operational Roles, (v) Simulation and Optimization

Table 2. Key features of $\mathrm{vF}$ and $\mathrm{Cmfg}$.

\begin{tabular}{lll}
\hline & \multicolumn{1}{c}{ vF } & \multicolumn{1}{c}{ Cmfg } \\
\hline Operational Boundaries & inter-factories & $\begin{array}{l}\text { Expand to multiple heterogeneous } \\
\text { cloud environments }\end{array}$ \\
\hline Data Interoperability & $\begin{array}{l}\text { common reference model for } \\
\text { unified data representation (VFDM) }\end{array}$ & $\begin{array}{l}\text { Ontology-based models as: OWL, RDF } \\
\text { XML description language }\end{array}$ \\
\hline Services Interoperability & \multicolumn{1}{c}{ service-oriented architecture } \\
\hline Operational Roles & $\begin{array}{l}\text { Distinguish between resources } \\
\text { consumer/provider and vF owner }\end{array}$ & Inherited from cloud computing \\
\hline Simulation and Optimization & $\begin{array}{l}\text { As an IT platform provide optimization by by } \\
\text { simulations of the } \\
\text { real plant of the factory }\end{array}$ & $\begin{array}{l}\text { SaaS applications to monitor } \\
\text { and controls the production process }\end{array}$ \\
\hline
\end{tabular}

Operational Boundaries. While one of the goals of a virtual factory is the enabling of a wide collaboration to expand the business outside company boundaries, cloud manufacturing encompasses resources virtualization, decentralized services, and collaborative deployment models to achieve enterprise collaboration. The concept of cloud manufacturing also includes dynamic resource allocation and different pricing models (i.e., pay-per-use, subscription, pay-for-resources), which not only opens up powerful forms of collaborations but also promotes a networked production process to support the emerging trend of the mass-customization.

Data Interoperability. One of the major challenges in a virtual factory is enabling interoperability among SMEs. To this end, different works have been proposed in the literature to support interoperability. The cloud-based storage architecture proposed by [40] promotes the sharing of data across virtual factory activities through a Storage as a Service cloud model. The storage is based on the concept of buckets, which are specific isolated storage spaces managing data for different data types. These buckets manage 
different types of data in multiple databases. In the European research project Virtual Factory Framework (VFF) [41], the proposed Virtual Factory Data Model (VFDM) provides a unified common definition of data shared among the software tools connected to the framework, using a shared meta-language. Similar challenges arise in cloud manufacturing, where the goal is to enable interoperability in heterogeneous environments composed of multiple cloud services. Authors in [41] propose to deal with data interoperability issues in cloud manufacturing with an architecture based on Virtual Function Blocks (VFB). Data manipulation is driven by function blocks, which guarantees the data related to the manufacturing process to be consistent among heterogeneous cloud environments. To this end, a Cloud manufacturing architecture [42] utilizes the Ontology Web Language (OWL) to model cloud resources, as well as other approaches which are proposed to provide a unified data modeling, such as ontology-based models (RDF and SPARQL) or cloud resource and service description based on XML language [41]. The described proposal enables interoperability over the three levels: (i) data transfer protocol, (ii) semantic of data, (iii) data presentation. Those solutions are based on the adoption of standard IT protocols like HTTP for data transfer, ontologies for providing semantic to the data (Resource Description Framework (RDF), OWL), and standard data format as the JSON format for data representation.

Service interoperability. In a virtual factory, a collaborative process includes the composition and integration of existing manufacturing services supported by technologies from the service-oriented computing (SOA) [43]. In cloud manufacturing, each manufacturing asset is virtualized via a virtual resource layer and deployed as a service through a serviceoriented layer, composing the cloud manufacturing architecture. For example, for virtual enterprises and collaborative networks, cloud manufacturing supports different forms of collaboration, such as loose coupling and tight coupling, and builds different forms of alliances through its highly flexible cloud architecture, as mentioned before. Cloud manufacturing enables the integration of decentralized social manufacturing assets to achieve high levels of sharing and collaboration. In cloud manufacturing, enterprises perform service development and provide manufacturing services to each other. It can be seen that the concept of cloud manufacturing and service-oriented manufacturing is completely consistent. Therefore, integration of cloud manufacturing services relies on the adoption of service-oriented architecture as in a virtual factory. As an example, we report the work of [44], in which authors propose a service-oriented architecture based on a service broker to orchestrate services of multiple heterogeneous clouds.

Operational Roles. The Cmfg paradigm differentiates operational roles, such as resource consumers, resources providers, and cloud operators. Although these roles are immutable in a standard cloud environment, as pointed out in the previous section, cloud manufacturing opens up new forms of collaborative models in which operational roles, as well as sharing policies, are interchangeable. Therefore, the roles of the actors in a multiple cloud collaborative environment need to be further studied to support a dynamic form of collaborations, flexible sharing policies, as well as diverse pricing models for each manufacturing asset. At the same time, the human role is taking into consideration during the design of a virtual factory [45]; in particular, the parties involved in a service-oriented virtual factory are defined as [43]: service resource, service provider, service consumer, and service broker. These roles, respectively, identify the parties which offer physical services, the consumer of these services, and the owner who controls and governs the virtual factory. Therefore, although the virtual factory roles are coherent with the ones defined in the $\mathrm{Cmfg}$, as proposed in the Cloud, deployment models, as well as pricing models, need to be further examined to enable a flexible collaboration between virtual factories.

Simulation and Optimization. From a virtual factory as an IT platform perspective, the potential is extended to plan, simulate, and control the shop floor to assess the future impact of production and maintenance planning decisions [46]. Similarly, in a cloud environment, cloud-based services monitor the production planning and control the discrete 
manufacturing environment (i.e., machine availability monitoring and collaborative and adaptive process planning [47], simultaneous shop scheduling, and material planning [48]).

\section{Building Blocks of a Factory of the Future}

After the analysis of each paradigm, we derive a reference framework for the realization of the digital twin model. Figure 8 reports the analyzed paradigms as well as the contribution to the realization of the factory of the future. The results highlight new features on different levels: IoT technologies are the core system for real-time data analysis and smart sensing and perception. This layer serves others layer as a data producer. Virtual models of the Digital Factory can benefit from the real-time data collected from the shop floor to enable virtual modeling of the real factory simulation and verification of the production processes. On the Digital Factory side, the digitalization of the intra-factory level opens up a new form of virtualization through the adoption of a 3D model-driven production (CAD), Augmented reality (AR), and Virtual Reality.

Conversely, the IoT plays a key role also for the realization of the Cmfg. Shifting from the intra-factory to the inter-factory levels where factories' capabilities are offered as a service, IoT enables a multi-model abstraction of factories' assets to govern the digital factory operations. In the $\mathrm{Cmfg}$, each manufacturing resource is abstracted and exposed as a Service according to the principles of Cloud Computing, enabling new forms of collaboration. Collaborative production, tracking materials, and shared production processes are enabled by the implementation of Cmfg platforms. As discussed previously, Cmfg is promoting the enablement of a new form of manufacturing processes, from which the concept of Service emerges. Hard manufacturing resources are abstracted in order to be offered and traded on Cmfg platforms as services. These platforms have different deployment models and enable collaboration on a different scale. Private Cloud refers to a Cloud infrastructure of exclusive usage of a single manufacturer. This option is suitable to benefit from the advantages of Cloud computing without offering services to external actors. On the contrary, Public Cloud is the deployment model enabling the shares of services. Public Cmfg infrastructure can be accessed by consumers to acquire and utilize a variety of services. These services can be in the form of software, platforms, or hardware. This deployment model is the most promising to the enablement of a new form of collaborative manufacturing process since its possible to open up services at an inter-factory level. Hybrid Cloud is a mixed model between public and private modes. As an example, a hybrid Cloud enables factory federation. Multiple factories can agree on sharing common infrastructure and build an exclusive platform on top of it where they execute their manufacturing process. This model opens up the concept of federated Cloud, in which companies organize their own process on the Cloud without actually offering services to the external entities. This form of collaboration is restricted at factory levels without going on public services. Meanwhile, there are multiples challenges to be addressed in order to realize a complete architecture for the digital-twin. Model accuracy and fidelity require a high and complete synchronization between virtual and real shop floor. This requires each entity of the shop floor to be mapped in the virtual space. As seen previously, this requires a high degree of interoperability between system entities, which is not always possible due to the high heterogeneity of technologies nowadays deployed on the shop floor and due to lack of standards. The role of the data in the digital twin model must be studied. New trends in Big Data and Deep Learning must be taken into account in order to maximize model simulations and optimization of design processes, but also for predicting failures and maximize the production processes. In this sense, models for smart analysis and prediction for manufacturing processes must also be studied in relation to computing capabilities enabled by the Cmfg. 


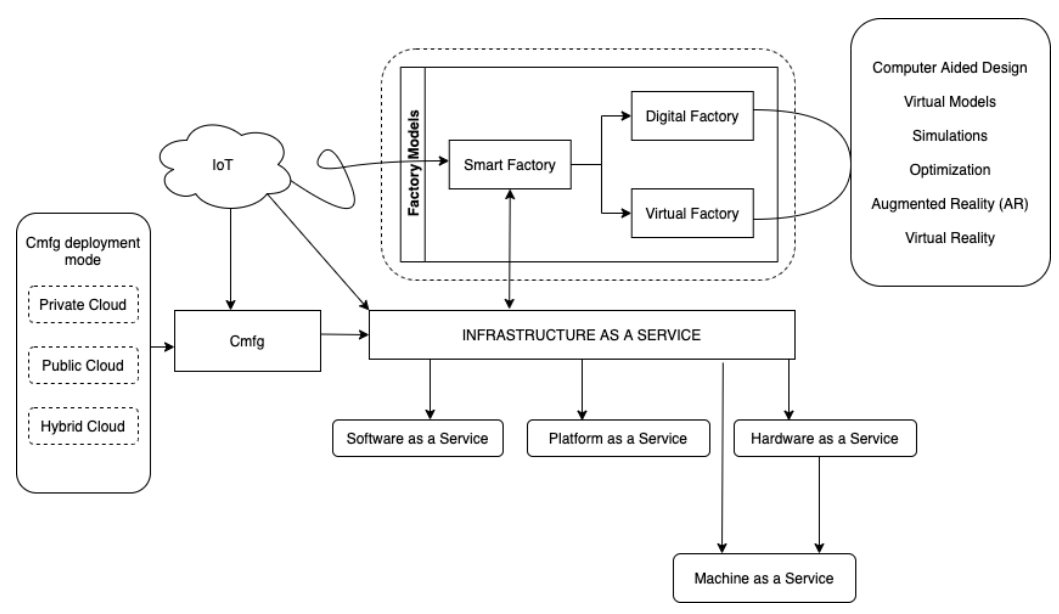

Figure 8. Factory of Future building blocks.

\section{Final Remarks}

In this section we report some discussion about our study and our conclusions, and we sketch some future work.

\subsection{Discussion}

The presented study highlights different trends for the realization of factories of the future, which involves applications of multiple technologies at different scales of the supply chain. As described in Section 6, the results highlight new features on different layers. At the lowest layer of the supply chain, IoT technologies are the core system for real-time data analysis, smart sensing, and perception. Thanks to these sensing capabilities, new forms of virtualization are enabled by the adoption of a 3D model-driven production (CAD), Augmented reality (AR), and Virtual Reality technologies typical in a Digital Factory. At an inter-factory level, each manufacturing resource is abstracted and exposed as a service according to the principles of Cloud Computing, enabling new forms of collaboration by offering collaborative production, tracking materials, and shared production processes enabled by cloud services traded over $\mathrm{Cmfg}$ platforms.

In this scenario, IoT plays the important role of enabling a multi-model abstraction of factories assets to govern the digital factory operations to the inter-factory level where factories' capabilities are offered as a service. Conversely, building accurate models of those complex systems requires a high and trustable synchronization between the virtual and real shop floor of the supply chain. This requires a high degree of interoperability between system entities. In this sense, the challenge of enabling data interoperability in the digital twin model must be further examined, as it plays the crucial role of enabling transparent communications among heterogeneous entities of the factories.

\subsection{Conclusions}

This review paper analyzed the state-of-art paradigms that emerged for realizing the Factory of the Future in the context of Industry 4.0 and China 2025, two programs we had experience of in the context of the FIRST H2020 project. As shown from the proposed study, digital factory and cloud manufacturing share the same goal of realizing the manufacturing plant digitalization with different characteristics. During the literature review, it emerged that $\mathrm{Cmfg}$ is much more popular in the Chinese scientific literature, while Digital Factories are popular in Europe. Motivated by these differences, the study aimed at identifying common characteristics as well as differences among those paradigms to determine relevance among the two, as well as point out main interoperability challenges that arise while integrating those two type of factories. From a common digital factory perspective, the aim is to automate and digitalize the intra-factory level with the help of new technological advancements, such as: virtual reality, augmented reality, and simulations to optimize the production of the shop floor. Instead, from an inter-factory collaboration 
perspective, the most promising paradigms are the paradigm of cloud manufacturing and the European concept of Virtual Factory. In this type of inter-communication, an emergent challenge regards the enablement of interoperability among factories; moreover, expanding business between European and Chinese factories requires further examining interoperability issues between Digital Factories and Cloud manufacturing.

\subsection{Future Work}

For an effective interoperability among those paradigms, as future work, we plan to review the state of the art in the application of software agents for the realization of the different activities related to the Digital Twin model.

In fact, as shown in this review paper, Digital Factories represent an enabling key paradigm to enhance global multi-tier supply chain agility, as it aims at using digital technologies to promote the integration of product design processes, manufacturing processes, and general collaborative business processes across factories and enterprises. A digital factory consists of multi-layered integration of the information related to various activities, along with the real factory and related resources.

From the point of view of software agents [49], they are decentralized software components that exhibit some main features, such as autonomy, reactivity, proactivity, and sociality, which can be enhanced with other ones such as mobility and learning capabilites; all these features lead them to be "intelligent" in a Distributed Artificial Intelligence (DAI) fashion [50]. Thanks to the features of software agents, a proper implementation adds flexibility to software systems and applications, thus leveraging the development of autonomous systems [51,52]. In particular, software agents have been considered in the development of digital abstractions, aiming at providing a means to manage real factories and all the required interactions in a flexible way.

Therefore, for our next study, we will research the state-of-the-art implementations of software agents for the realization of different activities related to the digital twin model.

Author Contributions: Investigation, G.S.; comparison of the two programs, G.S.; writing-original draft preparation, G.S.; writing - review and editing, L.L. and G.C.; project administration, G.C.; funding acquisition, G.C. All authors have read and agreed to the published version of the manuscript.

Funding: This work has been supported by the European Union in the framework of H2020 Marie Skłodowska-Curie Actions program, FIRST project, grant number 734599.

Institutional Review Board Statement: Not applicable.

Informed Consent Statement: Not applicable.

Data Availability Statement: Data sharing not applicable.

Conflicts of Interest: The authors declare no conflict of interest.

\section{References}

1. Hozdić, E. Smart factory for industry 4.0: A review. Int. J. Mod. Manuf. Technol. 2015, 7, 28-35.

2. Tao, F.; Cheng, J.; Qi, Q.; Zhang, M.; Zhang, H.; Sui, F. Digital twin-driven product design, manufacturing and service with big data. Int. J. Adv. Manuf. Technol. 2018, 94, 3563-3576. [CrossRef]

3. Li, L. China's manufacturing locus in 2025: With a comparison of "Made-in-China 2025" and "Industry 4.0". Technol. Forecast. Soc. Chang. 2018, 135, 66-74. [CrossRef]

4. Terkaj, W.; Tolio, T., The Italian Flagship Project: Factories of the Future. In Factories of the Future: The Italian Flagship Initiative; Springer International Publishing: Cham, Switzerland, 2019; pp. 3-35. [CrossRef]

5. Glaessgen, E.; Stargel, D. The digital twin paradigm for future NASA and U.S. air force vehicles. In Proceedings of the 53rd AIAA/ASME/ASCE/AHS/ASC Structures, Structural Dynamics and Materials Conference 20th AIAA/ASME/AHS Adaptive Structures Conference 14th AIAA, Honolulu, HI, USA, 23-26 April 2012. [CrossRef]

6. J, L. Scientific publication in China: An overview and some thoughts on improvement. Sci. Ed. 2004, 27, 120-121.

7. Webster, J.; Watson, R.T. Analyzing the Past to Prepare for the Future: Writing a Literature Review. MIS Q. 2002, 26, xiii-xxiii.

8. Lu, Y. Industry 4.0: A survey on technologies, applications and open research issues. J. Ind. Inf. Integr. 2017, 6, 1-10. [CrossRef]

9. Zhou, J.; Li, P.; Zhou, Y.; Wang, B.; Zang, J.; Meng, L. Toward New-Generation Intelligent Manufacturing. Engineering 2018, 4, 11-20. [CrossRef] 
10. Kuhn, W. Digital Factory - Simulation Enhancing the Product and Production Engineering Process. In Proceedings of the 2006 Winter Simulation Conference, Monterey, CA, USA, 3-6 December 2006; pp. 1899-1906. [CrossRef]

11. Jianzhong, T. Application Status and Prospects of Digital Factory. Innov. Technol. 2017, 5, 35-37.

12. Shoudian, L. Discussion on Digital Factory Construction Plan. Manufacturing Automation. Manuf. Autom. 2018, 40, 109-114.

13. Zhang, G.; Huang, G. Digital Factory: Its Application Situation and Trend. Aeronaut. Manuf. Technol. 2013, 40, $34-37$.

14. Nikolakis, N.; Alexopoulos, K.; Xanthakis, E.; Chryssolouris, G. The digital twin implementation for linking the virtual representation of human-based production tasks to their physical counterpart in the factory-floor. Int. J. Comput. Integr. Manuf. 2018, 32, 1-12. [CrossRef]

15. Lu, Y.; Xu, X. Resource virtualization: A core technology for developing cyber-physical production systems. J. Manuf. Syst. 2018, 47, 128-140. [CrossRef]

16. Vieira, G.E. Ideas for modeling and simulation of supply chains with arena. In Proceedings of the 2004 Winter Simulation Conference, Washington, DC, USA, 5-8 December 2004; Volume 2, pp. 1418-1427. [CrossRef]

17. Bzymek, Z.; Nunez, M.; Li, M.; Powers, S. Simulation of a Machining Sequence Using Delmia/Quest Software. Comput.-Aided Des. Appl. 2013, 5, 401-411. [CrossRef]

18. Gelenbe, E.; Guennouni, H. FLEXSIM: A flexible manufacturing system simulator. Eur. J. Oper. Res. 1991, 53, 149-165. [CrossRef]

19. Cang, V.T.; Bich, V.N.; Tuan, N. 3D Simulation-based Support Systems in PLM Solution for Offshore and Marine Industry-Which Way is for Vietnam's Shipbuilder? Mar. Eng. Front. 2013, 1, 82-89.

20. Bartkowiak, T.; Pawlewski, P. Reducing negative impact of machine failures on performance of filling and packaging production line-a simulative study. In Winter Simulation Conference (WSC); IEEE: Washington, DC, USA, 2016. [CrossRef]

21. Modoni, G.E.; Caldarola, E.G.; Sacco, M.; Terkaj, W. Synchronizing physical and digital factory: Benefits and technical challenges. Procedia CIRP 2019, 79, 472-477. [CrossRef]

22. Ojer, M.; Alvarez, H.; Serrano, I.; Saiz, F.A.; Barandiaran, I.; Aguinaga, D.; Querejeta, L.; Alejandro, D. Projection-Based Augmented Reality Assistance for Manual Electronic Component Assembly Processes. Appl. Sci. 2020, 10, 796. [CrossRef]

23. Radziwon, A.; Bilberg, A.; Bogers, M.; Madsen, E.S. The Smart Factory: Exploring Adaptive and Flexible Manufacturing Solutions. Procedia Eng. 2014, 69, 1184-1190. [CrossRef]

24. Zeid, A.; Sundaram, S.; Moghaddam, M.; Kamarthi, S.; Marion, T. Interoperability in Smart Manufacturing: Research Challenges. Machines 2019, 7, 21. [CrossRef]

25. Bicocchi, N.; Cabri, G.; Mandreoli, F.; Mecella, M. Dealing with data and software interoperability issues in digital factories. In Proceedings of the 25th International Conference on Transdisciplinary Engineering (TE2018), Modena, Italy, 3-6 July 2018; pp. 13-22. [CrossRef]

26. Shariatzadeh, N.; Lundholm, T.; Lindberg, L.; Sivard, G. Integration of Digital Factory with Smart Factory Based on Internet of Things. Procedia CIRP 2016, 50, 512-517. [CrossRef]

27. Hankel, M.; Rexroth, B. Industrie 4.0: The reference architectural model industrie 4.0 (RAMI 4.0). Frankfurt Am Main Ger ZVEI-German Electr. Electron. Manuf. Assoc. 2015. Available online: https: / / www.google.com/url?sa=t\&rct=j\&q=\&esrc=s\& source=web\&cd=\&ved=2ahUKEwj177C5quPzAhX7hf0HHRlaApwQFnoECAMQAQ\&url=https $\% 3 \mathrm{~A} \% 2 \mathrm{~F} \% 2 \mathrm{Fprzemysl}-40$ .pl\%2Fwp-content\%2Fuploads\%2F2010-The-Reference-Architectural-Model-Industrie-40.pdf\&usg=AOvVaw0OH2whrNthr8 uWHFOMloIY (accessed on 24 October 2021)

28. Weber, C.; Königsberger, J.; Kassner, L.; Mitschang, B. M2DDM-A Maturity Model for Data-Driven Manufacturing. Procedia CIRP 2017, 63, 173-178. [CrossRef]

29. Martin, R.; Lin, S.W.; Miller, B.; Durand, J.; Joshi, R.; Didier, P.; Chigani, A.; Torenbeek, R.; Duggal, D.; Bleakley, G.; et al. Industrial Internet Reference Architecture Technical Report; Technical Report; Industrial Internet Consortium: Boston, MA, USA, 2015. [CrossRef]

30. Fraile, F.; Sanchis, R.; Poler, R.; Ortiz, A. Reference Models for Digital Manufacturing Platforms. Appl. Sci. 2019, 9, 4433. [CrossRef]

31. Debevec, M.; Simic, M.; Herakovic, N. Virtual Factory as an Advanced Approach for Production Process Optimization. Int. J. Simul. Model. 2014, 13, 66-78. [CrossRef]

32. Phalp, K.; Xu, L.; De Vrieze, P.; Bai, Y.; Yu, H. Interoperability of the future factory: An overview of concepts and research challenges. Int. J. Mechatronics Manuf. Syst. 2020, 13, 3. [CrossRef]

33. $\mathrm{Xu}, \mathrm{X}$. From cloud computing to cloud manufacturing. Robot.-Comput.-Integr. Manuf. 2012, 28, 75-86. [CrossRef]

34. Rauch, E.; Seidenstricker, S.; Dallasega, P.; Hämmerl, R. Collaborative Cloud Manufacturing: Design of Business Model Innovations Enabled by Cyberphysical Systems in Distributed Manufacturing Systems. J. Eng. 2016. [CrossRef]

35. Yongkui, L.; Lijun, W.; Wei, W.; Xun, X. Discussion on cloud manufacturing. China Mech. Eng. 2018, 18, $2226-2237$.

36. Lu, Y.; Xu, X.; Xu, J. Development of a Hybrid Manufacturing Cloud. J. Manuf. Syst. 2014, 33, 551 - 566. [CrossRef]

37. Lin, Q.; Xia, K.; Wang, L.; Gao, L. Cloud manufacturing in China: A literature survey. Int. J. Manuf. Res. 2014, 9, 369-388. [CrossRef]

38. Li, B.; Zhang, G.J.; Shi, S.X. Mould industry cloud manufacturing platform supporting cooperation and its key technologies. Comput. Integr. Manuf. Syst. 2012, 18, 1620-1626. 
39. Li, B.; Zhang, L.; Chai, X.; Tao, F.; Ren, L.; Wang, Y.; Yin, C.; Huang, P.; Zhao, X.; Zhou, Z.; et al. Research and Applications of Cloud Manufacturing in China. In Cloud-Based Design and Manufacturing (CBDM): A Service-Oriented Product Development Paradigm for the 21st Century; Springer: Cham, Switzerland, 2014; pp. 89-126. [CrossRef]

40. Hao, Y.; Karbowski, R.; Shamsuzzoha, A.; Helo, P. Designing of Cloud-Based Virtual Factory Information System. In Advances in Sustainable and Competitive Manufacturing Systems; Springer: Cham, Switzerland, 2013. [CrossRef]

41. Wang, X.V.; Wang, L.; Gördes, R. Interoperability in cloud manufacturing: a case study on private cloud structure for SMEs. Int. J. Comput. Integr. Manuf. 2018, 31, 653-663. [CrossRef]

42. Tao, F.; Cheng, Y.; Xu, L.D.; Zhang, L.; Li, B.H. CCIoT-CMfg: Cloud Computing and Internet of Things-Based Cloud Manufacturing Service System. IEEE Trans. Ind. Inform. 2014, 10, 1435-1442. [CrossRef]

43. Schulte, S.; Schuller, D.; Steinmetz, R.; Abels, S. Plug-and-Play Virtual Factories. IEEE Internet Comput. 2012, 16, 78-82. [CrossRef]

44. V Parameswaran, A.; Chaddha, A. Cloud Interoperability and Standardization. SETLabs Briefings 2009, 7, 19-26.

45. Azevedo, A.; Francisco, R.; Bastos, J.; Almeida, A. Virtual factory framework: an innovative approach to support the planning and optimization of the next generation factories. IFAC Proc. Vol. 2010, 43, 320-325. [CrossRef]

46. Terkaj, W.; Tolio, T.; Urgo, M. A virtual factory approach for in situ simulation to support production and maintenance planning. CIRP Ann. 2015, 64, 451-454. [CrossRef]

47. Mourtzis, D.; Doukas, M.; Vlachou, A.; Xanthopoulos, N. Machine Availability Monitoring for Adaptive Holistic Scheduling: A Conceptual Framework for Mass Customization. Procedia CIRP 2014, 25, 406-413. [CrossRef]

48. Mourtzis, D.; Doukas, M.; Lalas, C.; Papakostas, N. Cloud-based Integrated Shop-floor Planning and Control of Manufacturing Operations for Mass Customisation. Procedia CIRP 2015, 33, 9-16. [CrossRef]

49. Wooldridge, M. An Introduction to Multiagent Systems; John Wiley \& Sons: New York, NY, USA, 2009.

50. Ferber, J.; Weiss, G. Multi-Agent Systems: An Introduction to Distributed Artificial Intelligence; Addison-Wesley Reading: Boston, MA, USA, 1999; Volume 1.

51. Savaglio, C.; Fortino, G.; Ganzha, M.; Paprzycki, M.; Bădică, C.; Ivanović, M., Agent-Based Computing in the Internet of Things: A Survey. In Intelligent Distributed Computing XI; Ivanović, M.; Bădică, C.; Dix, J.; Jovanović, Z.; Malgeri, M.; Savić, M., Eds.; Springer: Cham, Switzerland, 2018; pp. 307-320.

52. Fortino, G.; Russo, W.; Savaglio, C.; Shen, W.; Zhou, M. Agent-Oriented Cooperative Smart Objects: From IoT System Design to Implementation. IEEE Trans. Syst. Man Cybern. Syst. 2018, 48, 1939-1956. [CrossRef] 